\title{
Electro-Membrane Technology for Extraction of Valuable Compounds and Rare Earth Elements from the Red Mud
}

\author{
Gevork Anushavan Vartan ${ }^{1}$, Mishik Airazat Kazaryan², Gagik Gurgen Karamyan ${ }^{1}$, \\ Gagik Ashot Martoyan, * \\ ${ }^{1}$ Ecoatom LLC, Yerevan, Republic of Armenia \\ ${ }^{2}$ P. N. Lebedev Physical Institute, Russian Academy of Sciences, Moscow, Russian Federation
}

\section{Email address:}

gevork.v@gmail.com (G. A. Vartan), kazarmishik@yahoo.com (M. A. Kazaryan), gagik_karam@yahoo.com (G. G. Karamyan), martoian@yahoo.com (G. A. Martoyan)

${ }^{*}$ Corresponding author

\section{To cite this article:}

Gevork Anushavan Vartan, Mishik Airazat Kazaryan, Gagik Gurgen Karamyan, Gagik Ashot Martoyan. Electro-Membrane Technology for Extraction of Valuable Compounds and Rare Earth Elements from the Red Mud. American Journal of Applied Chemistry.

Vol. 6, No. 3, 2018, pp. 126-131. doi: 10.11648/j.ajac.20180603.15

Received: October 30, 2017; Accepted: July 25, 2018; Published: August 2, 2018

\begin{abstract}
The paper is devoted to the developed technology of treatment of red mud, a dangerous waste formed in the process of production of aluminum from bauxite ores by the Bayer process. The technology was examined on the samples of red mud from Russia and Iran aluminum plants. Detailed description of the process is presented. The chemical analysis data before and after the treatment are presented. It is shown that the new technology based on the use of electro-membrane apparatuses makes possible to neutralize the hazardous red mud with separate production of valuable compounds including rare earth metals. Several schemes of the process are presented.
\end{abstract}

Keywords: Red Mud, Processing, Electro-Membrane Methods, Rare Earth Elements

\section{Introduction}

Extraction of minor valuable or toxic elements from the industrial waste is an important task. In the process of aluminum production from bauxite ores the large quantities of waste in the form of red mud is formed [1]. According to [2], world production of aluminum in 2016 will be 60 million tons which, depending on the amount of bauxite and the process, provides the total amount of red mud waste between 60 and 120 million tons. Its chemical composition varies depending on the content and properties of leached bauxite. Usually, the red mud is stored in big tanks and tailings ponds which occupy vast areas suitable for agriculture, by that polluting soil and groundwater. Besides, its storage require adherence to strict rules because red mud is very toxic and aggressive compound.

Researches are being performed to find the use of red mud, and about 2 to 3 million tones are used annually in the production of cement [3], road construction [4] and as a source for metallic iron [5]. Potential applications include the production of low cost concrete [6] and bricks [7]. However in such way of utilization much of useful metals and compounds are lost. Besides, hazardous and toxic elements remain in building materials and can be washed away by rains and snow causing environment pollution.

In the previous paper it is described the basis of electromembrane technology for red mud processing with extraction of valuable elements [8]. Now it is presented more detailed description of the process including the schemes.

In the proposed technology the principal role belongs to electrodialysis process. Recently the Australian researchers from CSIRO's Mineral Resources Flagship also have used the electrodialysis process for treatment of red mud [9]. They leached it by sulfuric acid and in the end of the process they spitted the resulting $\mathrm{Na}_{2} \mathrm{SO}_{4}$ on $\mathrm{NaOH}$ and $\mathrm{H}_{2} \mathrm{SO}_{4}$ which has been delivered to the process beginning. However they were able only recover the silica from the mud and other compounds have not been extracted. In contrast to the presented approach they consider basically a neutralization task but not to reduce the cost of the process by extraction of 
valuable elements. Besides, the cost of produced $\mathrm{NaOH}$ and $\mathrm{H}_{2} \mathrm{SO}_{4}$ is higher than their commercial price. The process described in this paper is based on completely other approach.

\section{Experimental}

\subsection{Materials}

The samples of Bayer red mud were taken from an alumina refining plant in Ural (Russia) and Iran. Tables 1 and 2 show the average chemical composition of base metals.

Both samples had a moisture content of $40-60 \%$, the alkalinity $(\mathrm{pH})$ was $10-13$ and dispersity was less than 5 microns ( $80 \%$ fraction). As can be seen from the tables, the composition of both samples is roughly the same.

As the red mud contains a large amount of iron and aluminum, it seems it would be better to turn it into a source of valuable secondary raw material. But processing of red mud in undivided form is difficult task, since it contains too much of iron oxide to use as aluminum source, and it cannot be used as the iron ore as it contains too much aluminum oxide. Moreover, it also contains impurities of sulfur, phosphorus, calcium, silica, titanium, so it is necessary to find a method of processing based on a significant difference in chemical properties of these compounds and use it for their separation, or find a way to use this mixture as a raw material to produce the commercial or intermediate products.

\subsection{Chemical Analysis and Probe Preparation}

The analyses have been performed by ELAN 9000 ICP Mass Spectrometer, and high resolution optical microscope was used for measurements of particle size.

Table 1. Chemical composition of red mud from Ural (Russia) plant, wt\%.

\begin{tabular}{|c|c|c|c|c|c|c|c|c|}
\hline $\mathrm{Fe}_{2} \mathrm{O}_{3}$ & $\mathrm{CaO}$ & $\mathrm{SiO}_{2}$ & $\mathbf{A l}_{2} \mathrm{O}_{3}$ & MgO & $\mathrm{TiO}_{2}$ & $\mathbf{S}$ & $\mathbf{P}_{2} \mathbf{O}_{5}$ & $\mathrm{Na}_{2} \mathrm{O}$ \\
\hline $40-55$ & $8-11$ & $5-15$ & $14-16$ & $0.5-1.4$ & $2-5$ & up to 2 & $0.2-0.5$ & up to 2 \\
\hline
\end{tabular}

Table 2. Chemical composition of red mud from Iran plant, wt\%.

\begin{tabular}{|c|c|c|c|c|c|c|c|c|}
\hline $\mathrm{Fe}_{2} \mathrm{O}_{3}$ & $\mathrm{CaO}$ & $\mathrm{SiO}_{2}$ & $\mathbf{A l}_{2} \mathbf{O}_{3}$ & MgO & $\mathrm{TiO}_{2}$ & $\mathbf{S}$ & $\mathbf{P}_{2} \mathbf{O}_{5}$ & $\mathrm{Na}_{2} \mathrm{O}$ \\
\hline $44-46$ & $8-11$ & $8-9.5$ & $13-18$ & $0.2-1.6$ & $4-5$ & 3.6 & $0.2-0.65$ & $2.5-6.5$ \\
\hline
\end{tabular}

As can be seen from the tables, the composition of base metals in both samples is roughly the same. The amount of rare and rare earth elements is given in Tables 3 and 4.

Table 3. Composition of minor elements in red mud of aluminum production in $R F$.

\begin{tabular}{llll}
\hline Element & $\mathbf{g} / \mathbf{k g}$ & Element & $\mathbf{g} / \mathbf{k g}$ \\
\hline $\mathrm{Sc}$ & 0.025060 & $\mathrm{Cu}$ & 0.031695 \\
$\mathrm{Ti}$ & 31.446005 & $\mathrm{Zn}$ & 0.048848 \\
$\mathrm{~V}$ & 0.566959 & $\mathrm{Ge}$ & 0.004281 \\
$\mathrm{Cr}$ & 0.255851 & $\mathrm{Ga}$ & 0.035668 \\
$\mathrm{Mn}$ & 0.226875 & $\mathrm{As}$ & 0.027688 \\
$\mathrm{Fe}$ & 78.244009 & $\mathrm{Y}$ & 0.053365 \\
$\mathrm{Co}$ & 0.046470 & $\mathrm{Mo}$ & 0.029679 \\
$\mathrm{Ni}$ & 0.086609 & $\mathrm{Cd}$ & 0.000808 \\
\hline
\end{tabular}

Table 4. Composition of minor elements in red mud of aluminum production in Iran.

\begin{tabular}{llll}
\hline Element & g/kg & Element & g/kg \\
\hline $\mathrm{Sc}$ & 0.019358 & $\mathrm{Cu}$ & 0.068480 \\
$\mathrm{Ti}$ & 24.298205 & $\mathrm{Zn}$ & 0.235932 \\
$\mathrm{~V}$ & 0.277970 & $\mathrm{Ge}$ & 0.005525 \\
$\mathrm{Cr}$ & 0.151777 & $\mathrm{Ga}$ & 0.030868 \\
$\mathrm{Mn}$ & 2.974695 & $\mathrm{As}$ & 0.031339 \\
$\mathrm{Fe}$ & 78.037918 & $\mathrm{Y}$ & 0.001937 \\
$\mathrm{Co}$ & 0.078870 & $\mathrm{Mo}$ & 0.002424 \\
$\mathrm{Ni}$ & 0.303276 & $\mathrm{Cd}$ & 0.001026 \\
\hline
\end{tabular}

As it can be seen in addition to valuable elements, the red mood contains small quantities of rare earth elements ( $\mathrm{Sc}$ and Y). Experiments on extraction of useful compounds were carried out in own made laboratory setup allowing to change the working regimes and to assembly additional apparatuses. The setup has been provided by various reactors, tanks, pumps, electrochemical apparatuses (electrolyzers and electrodialyzers), dryers, and all necessary components. The principal of technology is based on the leaching of red mud by strong oxidizer, the sodium hypochlorite.

\section{Results}

In the result of investigations the red mud has been successfully leached, the dissolved and undissolved parts were separated. Its alkalinity $(\mathrm{pH})$ has already reduced to 7 9 that is neutral.

The aqueous concentrate of rare, rare earth and other valuable elements were obtained. Solutions were periodically analyzed by the mass spectrometer, and the time of process completion was determined. Simultaneously the chemical composition of the processed red mud has been analyzed by the above mentioned equipment (Table 5 and 6). The undissolved part has been treated by complex schemes (see Figures 1 - 4).

Table 5. Composition of Russian red mud after processing.

\begin{tabular}{llll}
\hline Element & $\mathbf{m g} / \mathbf{k g}$ & Element & $\mathbf{m g} / \mathbf{k g}$ \\
\hline $\mathrm{Sc}$ & 0.092628 & $\mathrm{Cu}$ & 1.248894 \\
$\mathrm{Ti}$ & 0.989895 & $\mathrm{Zn}$ & 1.497201 \\
$\mathrm{~V}$ & 2.831367 & $\mathrm{Ge}$ & 0.003759 \\
$\mathrm{Cr}$ & 0.363909 & $\mathrm{Ga}$ & 0.864186 \\
$\mathrm{Mn}$ & 0.011424 & $\mathrm{As}$ & 0.714249 \\
$\mathrm{Fe}$ & 1.405755 & $\mathrm{Y}$ & 0.001866 \\
$\mathrm{Co}$ & 0.002025 & $\mathrm{Mo}$ & 1.217775 \\
\hline
\end{tabular}


Table 6. Composition of Iranian red mud after processing.

\begin{tabular}{llll}
\hline Element & $\mathbf{m g} / \mathbf{k g}$ & Element & $\mathbf{~ m g} / \mathbf{k g}$ \\
\hline $\mathrm{Sc}$ & 0.136449 & $\mathrm{Cu}$ & 2.043684 \\
$\mathrm{Ti}$ & 1.462806 & $\mathrm{Zn}$ & 1.629492 \\
$\mathrm{~V}$ & 29.265636 & $\mathrm{Ge}$ & 0.003486 \\
$\mathrm{Cr}$ & 0.636222 & $\mathrm{Ga}$ & 0.226401 \\
$\mathrm{Mn}$ & 0.134481 & $\mathrm{As}$ & 1.483803 \\
$\mathrm{Fe}$ & 5.904255 & $\mathrm{Y}$ & 0.004251 \\
$\mathrm{Co}$ & 0.004638 & $\mathrm{Mo}$ & 0.092148 \\
$\mathrm{Ni}$ & 0.022359 & $\mathrm{Cd}$ & 0.000561 \\
\hline
\end{tabular}

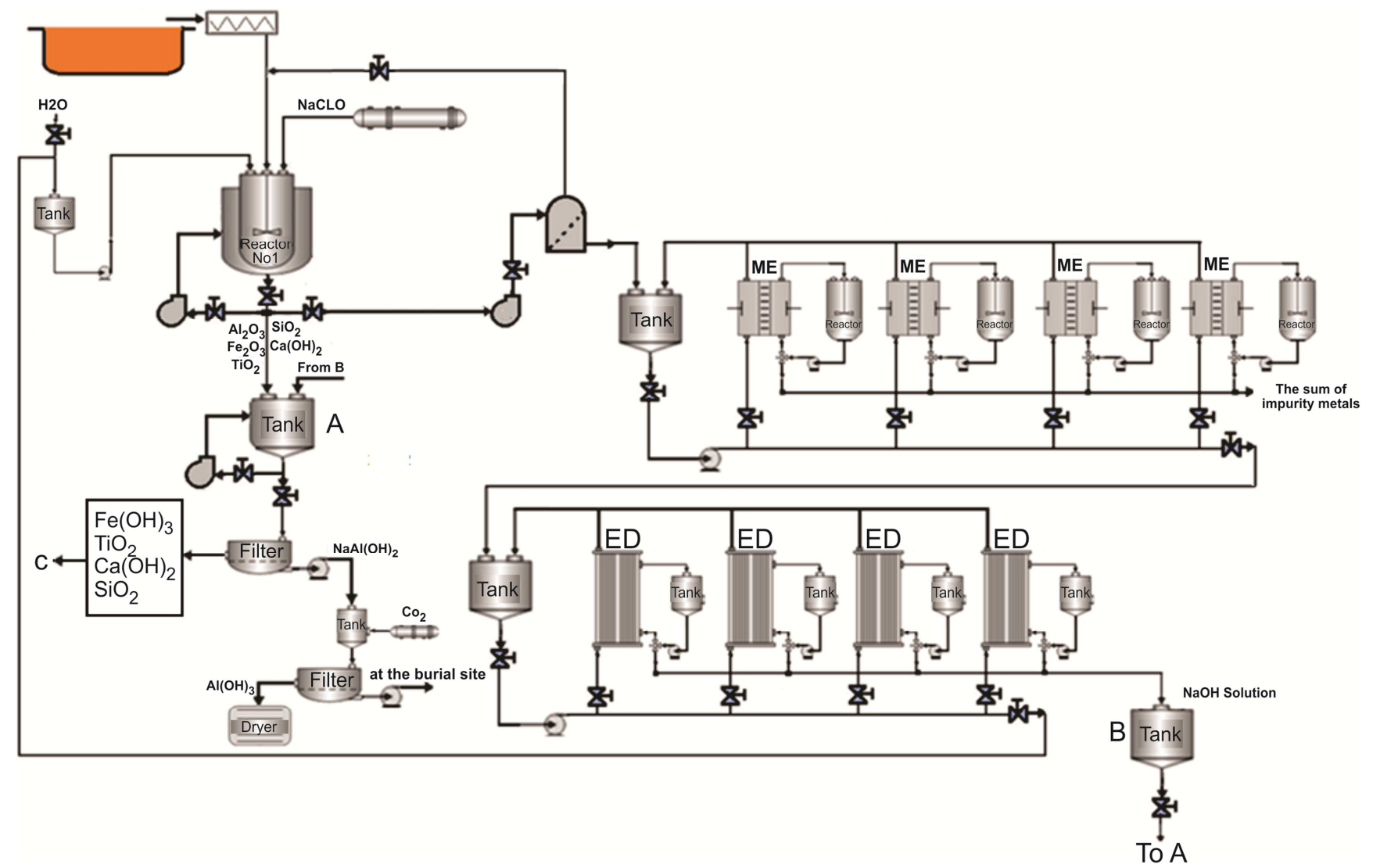

Figure 1. General scheme of red mud processing.

As it shown in Figure 1 the processing of red mud begins with the filling of stirred reactor 1 by the red mud, together with purified water and calculated amount of sodium hypochlorite. Here the general diagram shows the route of extraction of alumina and soluble compounds of rare earth elements as well as compounds of iron, titanium, calcium and silicon. The sodium hypochlorite is prepared in special unit presented in Figure 2. After mild leaching of red mud the undissolved residues $\left(\mathrm{Al}_{2} \mathrm{O}_{3}, \mathrm{SiO}_{2}, \mathrm{Fe}_{2} \mathrm{O}_{3}, \mathrm{Ca}(\mathrm{OH})_{2}, \mathrm{TiO}_{2}\right.$ and other minor elements) are moved to the tank A. Besides, the iron sulfate solution and sodium aluminates from B (see Figure 3) are added in tank A. In the results of reaction occurred in tank A and after treatment by filter press the mixture of oxides $\left(\mathrm{SiO}_{2}, \mathrm{Fe}_{2} \mathrm{O}_{3}, \mathrm{Ca}(\mathrm{OH})_{2}, \mathrm{TiO}_{2}\right)$ is formed
As shown in Tables 5 and 6, the composition of useful elements in the red mud is significantly decreased after treatment, suggesting that most of them are passed and concentrated in the solution. For example, the amount of scandium is reduced in about 100 times. On the base of performed experiments it is designed the large scale processing plant the diagram of which is shown in the Figure 1. This is a scheme for separate module where the quantity of units and their parameters are selected so to ensure the productivity of red mud utilization in amount of 5t/hour. 


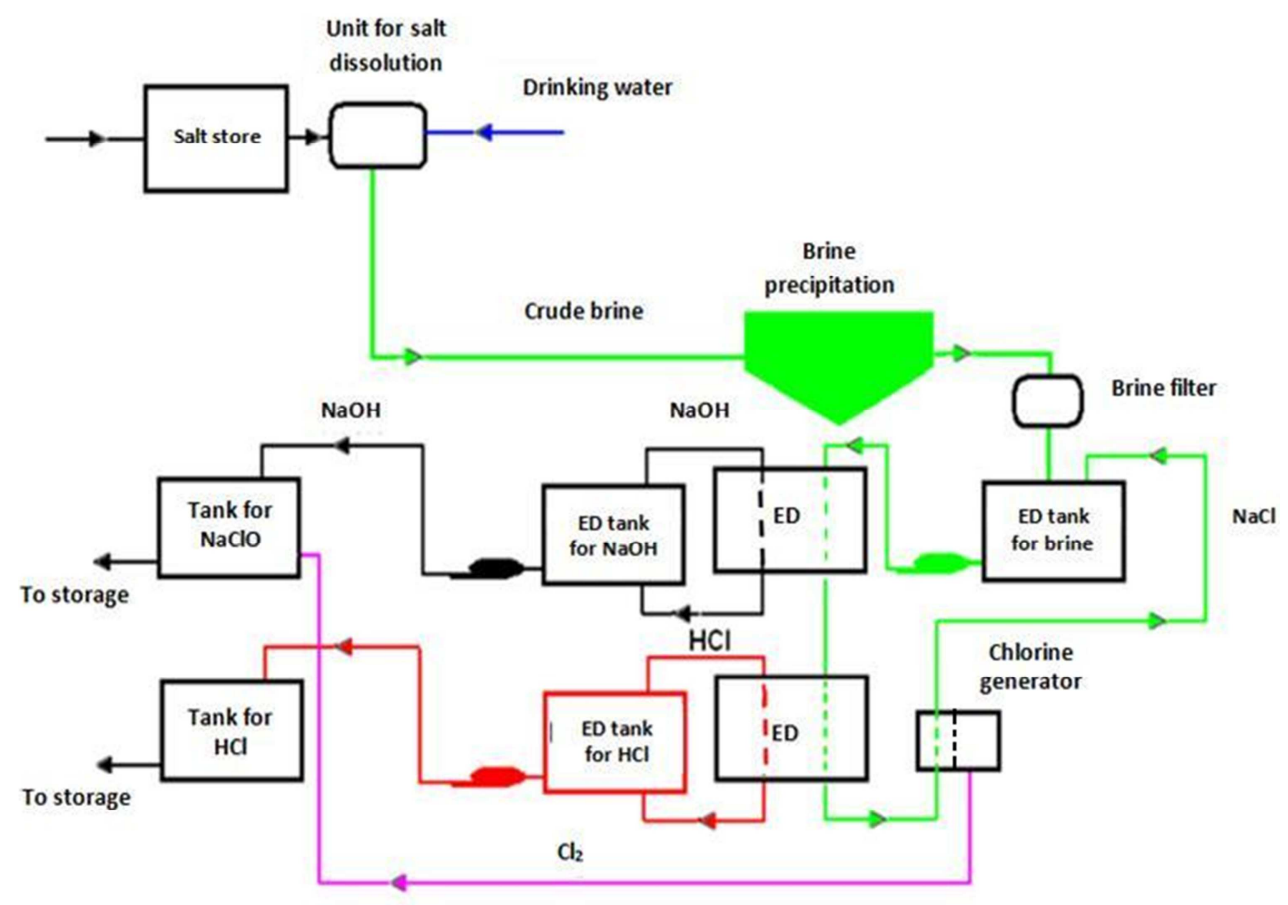

Figure 2. Scheme of preparation of sodium hypochlorite by electro-membrane technology.

On site production of sodium hypochlorite $(\mathrm{NaClO})$ is based on the new technology of electrodialysis of sodium chloride. First the salt is dissolved by pure water in special reactor and crude brine is moved into brine precipitation reactor, where the undissolved impurities are precipitated, and the solution is additionally cleaned by brine filter and enters the special tank. From this tank the solution is pumped into electrodialyzer were under the action of electric potential it dissociates into $\mathrm{Na}^{+}$and $\mathrm{Cl}^{-}$ions which are separated by ion-exchange membranes and form the sodium hydroxide and chlorine containing gas.

The sodium hydroxide is accumulated in the special tank and pumped into the tank for $\mathrm{NaClO}$ generation. The solution of sodium chloride is moved to another (bottom) electrodialyzer were in connected electrodialyzer the hydrochloric acid is formed. The chlorine is produced in special generator and pumped to the tank for sodium hypochlorite, and obtained pure hydrochloric acid is stored in the tank for $\mathrm{HCl}$ for various applications.

As it is known the regular method of $\mathrm{NaClO}$ production is based on mixing of $\mathrm{NaOH}$ with chlorine gas. But the proposed method allows to produce additionally the $\mathrm{HCl}$. According to this scheme, if the production of hydrochloric acid is needed, the power supply of chlorine generator is disconnected and electrodialyzer for $\mathrm{HCl}$ production is turned on. In the case when $\mathrm{NaClO}$ is needed to get, the opposite operation is carried out, the electrodialyzer for $\mathrm{HCl}$ production is disconnected and chlorine generator is turned on.

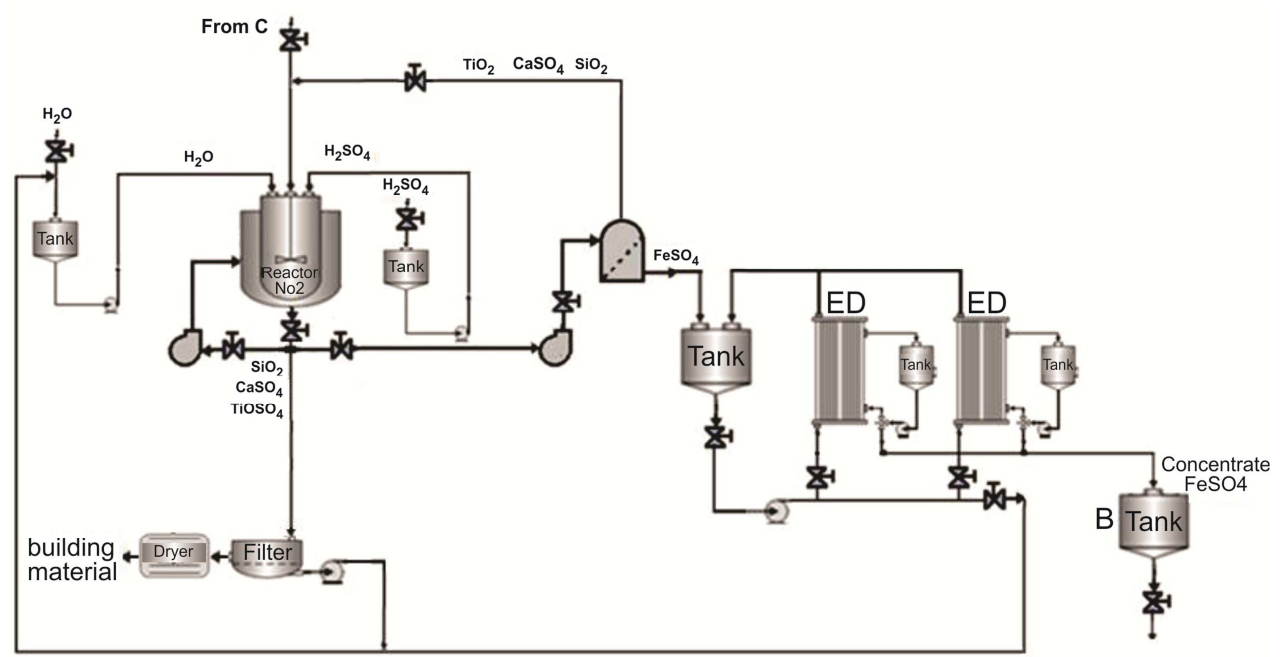

Figure 3. Scheme of treatment of compounds obtained from the process $C$. 
In the Figure 3 the further processing and extracting of base compounds of iron, titanium, calcium and silicon is shown. Here the residues from $\mathrm{C}$ are transferred to the stirred reactor 2 where purified water and sulfuric acid are added. After treatment the titanyl sulfate $\left(\mathrm{TiOSO}_{4}\right)$ and calcium sulfate (gypsum) are formed. The latter together with silica is separated and can be used as building materials while titanyl sulfate is directed to further processing with production of titanium dioxide and sulfuric acid (see also Figure 4). The solution of iron sulfate from the reactor 2 is moved through the filter into the system of electrodialyzers where it is concentrated and can be used as a commercial product or converted into the iron oxide and then to metallic iron.

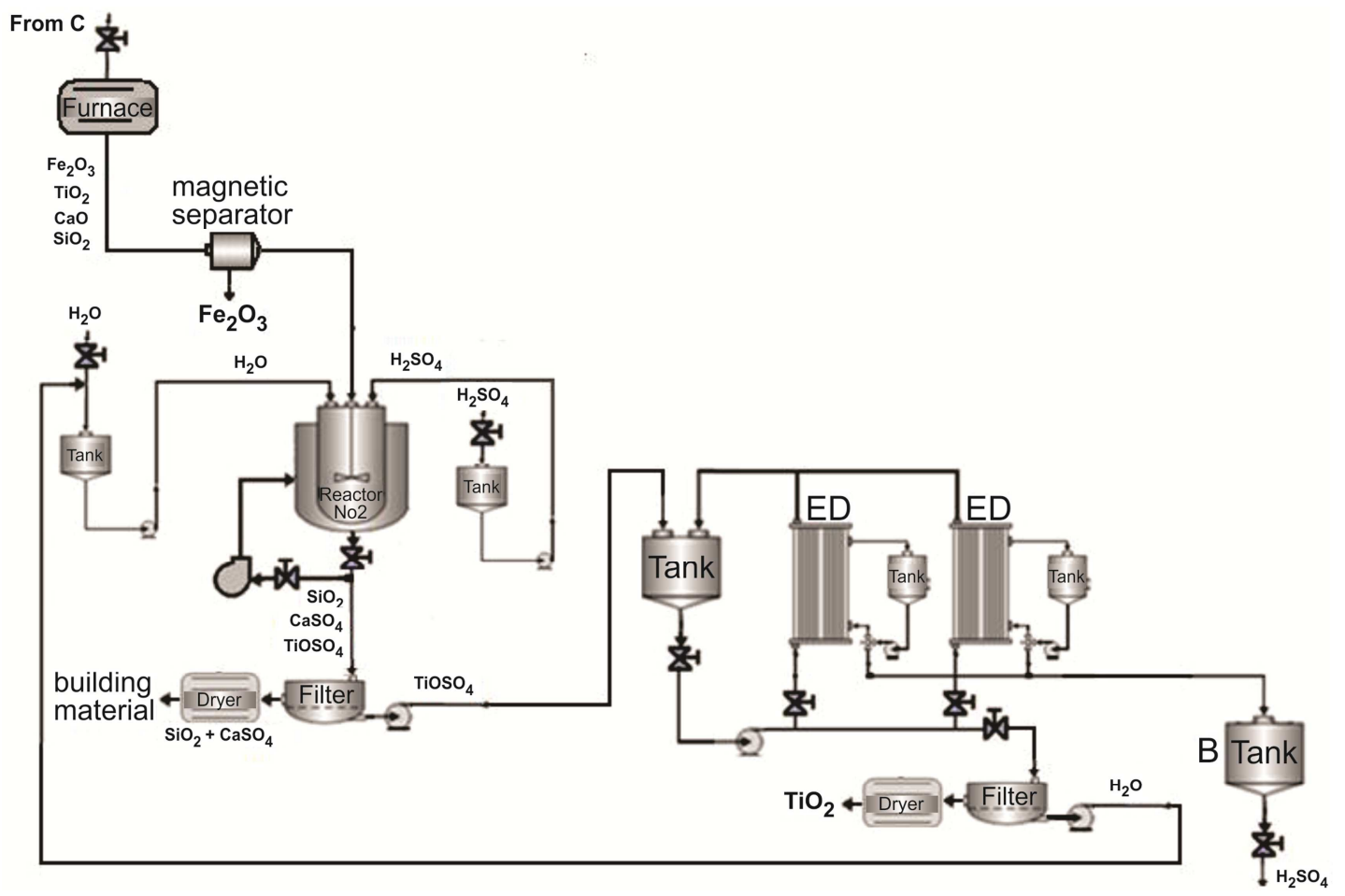

Figure 4. Another scheme (version) of processing the base metals obtained from the process $C$.

This technological process begins with the drying of metal hydroxides in the furnace and their passing through magnetic separator where magnetite $\mathrm{Fe}_{3} \mathrm{O}_{4}$ is extracted. Then the remaining part is processed by the method presented in Figure. 4. Here the titanyl sulfate solution is subjected to the electrodialysis process with separation of sulfuric acid and titanium dioxide. So, the full separation of base useful compounds is achieved.

As for the rest of dissolved part of red mud containing in the sum of impurity metals (see Table 2) it can be then treated in another unit by production of separate elements.

As shown from Tables $3-6$, the composition of useful elements in the red mud is significantly decreased after treatment, suggesting that the most of them are passed into the solution.

The subsequent separation of these elements in pure metallic form is the subject of future studies, but it is necessary to consider it to describe the possible method of processing. Various organizations conduct laboratory experiments to extract valuable metals. For example, the pyrometallurgical method based on reduction of red mud by smelting to obtain a slag rich in valuable elements with further dissolving of slag in respective solutions, its smelting accompanied by separation of solid and liquid fractions, and then the complex processing by cooling and recrystallization is described in [10].

Another approach to the separation of rare earth elements is based on the cascade of centrifugal extractors which is designed by LLC "LIT" of companies group "Skaygrad" (Moscow) [11]. Similar technologies of scandium extraction are developed also in National University of Science and Technology (MISIS) [12].

The authors of presented paper propose another method for separation of rare, rare earth and other valuable metals using the membrane electrolysis based on the difference in electrochemical potentials of metal deposition [13].

In this process based also on electro-membrane method (electrolysis and electrodialysis) the metals to be separated are deposited on the cathode or sedimented as powder under influence of selected electric potential. For each element to be extracted during the cycling, a special membrane electrolyzer is provided, and, by particular software, a corresponding potential is applied to the each electrolyzer, which is determined by standard potential of this element. In this case all other electrolyzers should be disconnected. If some elements are not extracted in one pass they will be separated in the next one. The process of cycling will be continued until all elements will be extracted. 


\section{Conclusions}

The proposed technology of red mood processing allows:

To produce valuable compounds of base metals containing in the red mood such as $\mathrm{Al}_{2} \mathrm{O}_{3}, \mathrm{SiO}_{2}, \mathrm{Fe}_{2} \mathrm{O}_{3}, \mathrm{Fe}, \mathrm{FeSO}_{4}$, $\mathrm{Ca}(\mathrm{OH})_{2}, \mathrm{CaSO}_{4}, \mathrm{TiO}_{2}$ and others.

To produce important liquid chemicals such as $\mathrm{NaClO}$, $\mathrm{NaOH}$ and $\mathrm{HCl}$ which can be used for process continuation or as secondly commercial products.

To extract valuable minor rare and rare earth elements. At the same time to extract separately and neutralize the toxic elements which can be contained in the red mood such as As, $\mathrm{Hg}$, etc.

The technology is economically and environmentally sound because it operates in closed cycle regime.

\section{References}

[1] S. K. Ritters, "Making the most of red mud", Chemical and Engineering News, vol. 92, No. 8, pp. 33-35, 2014.

[2] Information on http://www.aluminiumleader.com/economics/how_aluminium _market_works.

[3] Y. Pontikes and G. N. Angelopoulos, "Bauxite residue in cement and cementitious applications", Resourc. Conserv. Recyl., vol. 73, pp. 53-63. 2013.

[4] W. K. Biswas and D. J. Cooling, "Sustainability Assessment of Red Sand TM as a substitute for Virgin Sand and Crushed Limestone", J. of Ind. Ecology, vol. 17, No. 5, pp. 756-762, 2013.

[5] C. Schmitz, "Red Mud Disposal in Handbook of aluminium recycling", Vulkan-Verlag GmbH, p. 18, 2006.
[6] W. Liu, J. Yang, B. Xiao, "Review on treatment and utilization of bauxite residues in China", Int. J. Miner. Process. vol. 93, pp. 220-231, 2009.

[7] A. Garg, H. Yadav, "Study of Red Mud as an Alternative Building Material for Interlocking Block Manufacturing in Construction Industry", International Journal of Materials Science and Engineering, vol. 3, No. 4, pp. 295-300, 2015.

[8] G.A. Martoyan, G.G. Karamyan and G.A. Vardan, "New technology of extracting the amount of rare earth metals from the red mud", REES-2015 IOP Publishing IOP Conf. Series: Materials Science and Engineering, vol. 112, pp. 1-5, 2016.

[9] P. Smith, "Aluminium future out of red mud treatment", Resourceful, No. 7, p. 6, 2015.

[10] A.A. Golubev and Yu.A. Gudim, "Method of Pyrometallurgical Processing of Red Mud", Patent WO $2013070121 \mathrm{~A} 1,2013$.

[11] A. M. Abramov, Yu. B. Sobol, Zh. N. Galieva, O. I. Volobuev, A. S. Solodovnikov and A. A. Yachmenev, "Organization of REM production at complex processing of phosphogypsum", [in] Proceedings of All-Russian Con. on Rare Earth Materials, Tomsk, 2013 (in Russian).

[12] A. Medvedev, R. Khayrullina, S. Kirov, A. Suss, "Technical scandium oxide obtaining from red mud of urals aluminium smelter", Tsvetnye Metally, No. 12, pp. 47-52, 2015, (in Russian),

[13] Z. G. Guiragossian, G. A. Martoyan, S. G. Intsheyan, G. G. Nalbandyan and S. G. Tonikyan, "The extraction of heavy metals by means of a new electrolytic method", [in] Proceedings of WM'04 Conf., Tucson,, p. 4304, 2004. 